density around the MCP joints deteriorate in the preclinical phase of RA, which is mostly prominent in the trabecular bone. Modelling (Figure 1B) suggests that trabecular bone loss around the MCP joints has a constant pace regardless of the clinical status. Whereas the radial bone densities are relatively stable in the preclinical phase and show a reduction after the clinical onset of RA. Age and sex adjusted hazard ratios $(95 \% \mathrm{Cl})$ for the risk of RA clinical onset were 1.52 (1.03 to $2.25)$ for radius D100 and 1.66 (1.07 to 2.55) for radius DComp (Table-1). Conclusion: Metacarpal bone showed a constant decline that started already in the pre-phase of RA and continued after its clinical onset. In contrast, bone loss in the radius was not observed in the pre-phase but started at onset of RA. Low radial VBMD in the pre-clinical phase, however, was associated with a higher risk of RA onset. These findings suggest different spatiotemporal dynamics of bone loss before and after RA onset

REFERENCES:

[1] Kleyer A. et. al. Ann Rheum Dis. 2014, 73:854-60

[2] Simon D. et. al. Ann Rheum Dis. 2020, doi:10.1002/art.41229

Disclosure of Interests: None declared

DOI: 10.1136/annrheumdis-2021-eular.4176

\section{OP0149 RELIABILITY AND RESPONSIVENESS OF TWO OMERACT WHOLE-BODY MRI SCORES OF ENTHESEAL AND JOINT INFLAMMATION IN THE KNEE REGION IN SPONDYLOARTHRITIS}

M. Wetterslev ${ }^{1,2}$, W. P. Maksymowych ${ }^{3,4}$, R. G. Lambert ${ }^{5,6}$, I. Eshed ${ }^{7}$, S. Juhl Pedersen $^{1}$, M. Stoenoiu ${ }^{8}$, S. Krabbe ${ }^{1}$, P. Bird ${ }^{9}$, V. Foltz ${ }^{10}$, A. J. Mathew ${ }^{1,2}$ F. Gandjbakhch ${ }^{10}$, J. Paschke ${ }^{4}$, P. Carron ${ }^{11,12}$, G. De Marco ${ }^{13,14}$, H. MarzoOrtega $^{13,14}$, A. E. F. Poulsen ${ }^{1}$, J. L. Jaremko ${ }^{5}$, P. G. Conaghan ${ }^{13,14}$, M. Østergaard ${ }^{1,2}$ on behalf of the OMERACT MRI in Arthritis Working Group ${ }^{1}$ Rigshospitalet, Copenhagen Center for Arthritis Research, Center for Rheumatology and Spine Diseases, Copenhagen, Denmark; ${ }^{2}$ University of Copenhagen, Department of Clinical Medicine, Copenhagen, Denmark; ${ }^{3}$ University of Alberta, Department of Medicine, Edmonton, Alberta, Canada: ${ }^{4}$ CARE Arthritis, Edmonton, Alberta, Canada; ${ }^{5}$ University of Alberta, Department of Radiology and Diagnostic Imaging, Edmonton, Alberta Canada; ${ }^{6}$ Medical Imaging Consultants, Edmonton, Alberta, Canada; ${ }^{7} \mathrm{Tel}$ Aviv University, Department of Diagnostic Imaging, Sheba Medical Center, Affiliated to the Sackler School of Medicine, Israel; ${ }^{8}$ Université catholique de Louvain, Department of Rheumatology, Cliniques Universitaires SaintLuc, Institut de Recherche Expérimentale et Clinique, Brussels, Belgium; ${ }^{9}$ University of New South Wales, Division of Medicine, Sydney, Australia;

${ }^{10}$ Sorbonne University, Department of Rheumatology, APHP, PitiéSalpêtrière Hospital, Paris, France: ${ }^{11}$ Ghent University Hospital, Department of Rheumatology, Ghent, Belgium; ${ }^{12}$ Ghent University, VIB Inflammation Research Centre, Ghent, Belgium; ${ }^{13}$ University of Leeds, Leeds Institute of Rheumatic and Musculoskeletal medicine, Leeds, United Kingdom; ${ }^{14} \mathrm{NIHR}$ Leeds Biomedical Research Centre, Leeds Teaching Hospitals NHS Trust, Leeds, United Kingdom

Background: Inflammation in peripheral joints and entheses is common in spondyloarthritis $(\mathrm{SpA})$. Whole-body magnetic resonance imaging (WB-MRI) allows assessment of the overall inflammatory status of arthritis patients including joints and entheses. The OMERACT MRI Whole-body scoring system for Inflammation in Peripheral joints and Entheses (MRI-WIPE) [1] has been developed and validated for the entire body assessment, including the knee, but not separately validated for the knee joint region. Detailed MRI scoring systems exist for heels, hands and feet, but although knee arthritis is a key cause of functional impairment, no detailed scoring system has been validated for inflammatory arthritides.
The Knee Inflammation MRI Scoring System (KIMRISS) [2] was developed and validated in osteoarthritis and demonstrated good reliability.

Objectives: To perform region-based development of whole-body MRI through validation of two knee region scoring systems in $\mathrm{SpA}$.

Methods: Assessment of inflammation was performed in the knee region on sagittal WB-MRIs using 2 scoring systems, MRI-WIPE and KIMRISS (Figure 1), in 4 iterative multi-reader exercises. In the final exercise, images (psoriatic arthritis, axial and peripheral $\mathrm{SpA}$ ) were obtained before and after TNF-inhibitor.

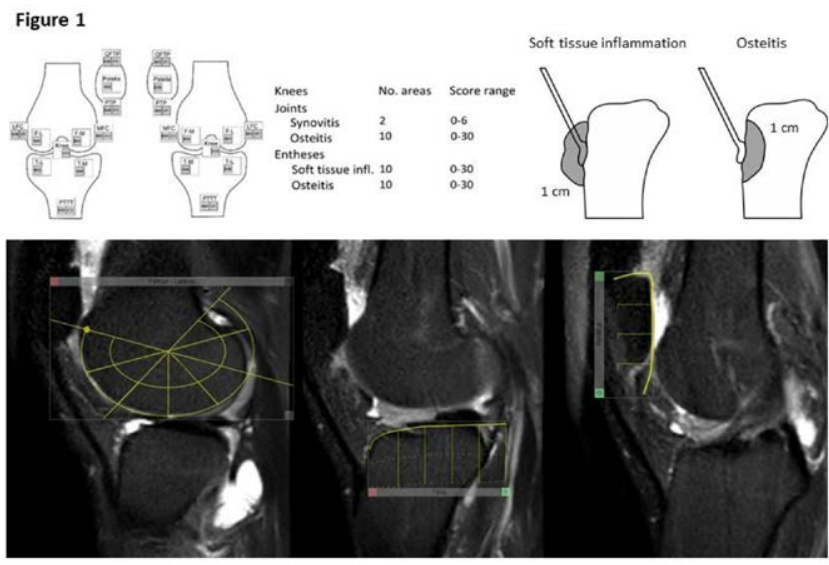
[1]; Upper row, right: schematic drawing of the principle of scoring osteitis and soft tissue inflammation [1]. Usprated by the tibing

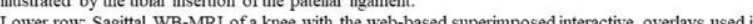
KIMRISS for osteitis scoring positioned for femur, tibia and patells.

Results: In the final exercise (exercise 4), reliability was mostly good for experienced readers with the overall highest interreader agreement in the previous exercise (exercise 3). Median pairwise single measure intraclass correlation coefficients for osteitis and synovitis/effusion for status/change were $0.71 / 0.48$ (WIPE osteitis), 0.48/0.77 (WIPE synovitis/effusion), 0.59/0.91 (KIMRISS osteitis) and 0.92/0.97 (KIMRISS synovitis/effusion) (Table 1). Wilcoxon signed-rank test showed significant change in synovitis/effusion for both methods and they correlated significantly regarding status in osteitis $(0.92, \mathrm{p}<0.001)$ and synovitis effusion $(0.89, p=0.001)$ and change in synovitis/effusion $(0.89, p<0.001)$. Stand ardized response mean was 0.74 (WIPE synovitis/effusion) and 0.78 (KIMRISS synovitis/effusion).

Conclusion: MRI-WIPE and KIMRISS may both be useful as part of modula whole-body evaluation in clinical studies.

REFERENCES:

[1] Krabbe S et al. J Rheum. 2019;46(9):1215-21

[2] Jaremko JL et al. RMD Open. 2017;3(1):e000355

Acknowledgements: We thank CARE Aarthritis Limited (carearthritis.com) fo help with setting up the web-based scoring interface, the scoring exercises, and the web-based meetings. We thank all who participated in the SIG (Special Interest Group) virtual OMERACT meeting 29 October 2020. HMO, GDM and PGC are supported in part by the National Institute for Health Research (NIHR) Leeds Biomedical Research Centre, United Kingdom. The views expressed in this study are those of the authors and not necessarily those of the NHS, the NIHR or the Department of Health.

Disclosure of Interests: Marie Wetterslev: None declared, Walter P Mak symowych Speakers bureau: AbbVie, Janssen, Novartis, Pfizer and UCB,

Table 1. MRI-WIPE knee and KIMRISS interreader reliability for OMERACT exercises 3 and 4

\begin{tabular}{|c|c|c|c|c|c|c|c|c|c|c|}
\hline \multirow[b]{3}{*}{ Variables } & \multirow[b]{3}{*}{ No. patients } & \multirow[b]{3}{*}{ Type of score } & \multicolumn{4}{|c|}{ MRI-WIPE Knee } & \multicolumn{4}{|c|}{ KIMRISS } \\
\hline & & & \multicolumn{2}{|c|}{ Osteitis } & \multicolumn{2}{|c|}{ Synovitis/effusion } & \multicolumn{2}{|c|}{ Osteitis } & \multicolumn{2}{|c|}{ Synovitis/effusion } \\
\hline & & & Mean score & ICC & Mean score & ICC & Mean score & ICC & Mean score & ICC \\
\hline \multirow[t]{2}{*}{ Exercise 3} & 11 & Status & $3.6(0-16)$ & $0.57(-0.06-0.98)$ & $1.8(0-4)$ & $0.47(0.05-0.85)$ & $32.3(1-224)$ & $0.87(0.66-0.99)$ & $29.9(11-60)$ & $0.34(-0.62-0.87)$ \\
\hline & 11 & Change & $1.1(-2-6)$ & $0.53(0.03-0.90)$ & $0(-2-1)$ & $0.32(-0.13-0.76)$ & $27.7(-9-131)$ & $0.58(-0.30-0.96)$ & $-1.6(-33-11)$ & $0.48(-0.32-0.95)$ \\
\hline \multicolumn{11}{|l|}{9 readers } \\
\hline \multirow[t]{2}{*}{ Exercise 3} & 11 & Status & $3.1(0-16)$ & $0.83(0.71-0.97)$ & $2.5(0-5)$ & $0.59(0.51-0.71)$ & $34.4(0-233)$ & $0.89(0.83-0.99)$ & $36.5(16-78)$ & $0.59(0.08-0.86)$ \\
\hline & 11 & Change & $0.9(-3-6)$ & $0.72(0.57-0.83)$ & $0(-2-1)$ & $0.63(0.49-0.76)$ & $19.3(-23-86)$ & $0.46(0.18-0.83)$ & $-1.8(-45-17)$ & $0.89(0.82-0.95)$ \\
\hline \multicolumn{11}{|l|}{3 readers } \\
\hline \multirow[t]{2}{*}{ Exercise 4} & 10 & Change & $-0.25(-4-5)$ & $0.38(-0.35-0.94)$ & $-1.0(-3-1)$ & $0.30(-0.43-0.89)$ & $-0.45(-37-65)$ & $0.26(-0.86-0.97)$ & $-14.7(-48-0.20)$ & $0.48(-0.39-0.99)$ \\
\hline & 20 & Status & $2.9(0-7)$ & $0.50(-0.01-0.84)$ & $2.1(0-4)$ & $0.44(-0.21-0.79)$ & $15.2(0-66)$ & $0.35(-0.04-0.89)$ & $55.6(1-122)$ & $0.54(0.01-0.96)$ \\
\hline \multicolumn{11}{|l|}{9 readers } \\
\hline \multirow[t]{2}{*}{ Exercise 4} & 10 & Change & $0.2(-2-6)$ & $0.48(0.16-0.66)$ & $-1.4(-5-0)$ & $0.77(0.70-0.82)$ & $5.8(-27-111)$ & $0.92(0.90-0.94)$ & $-20.7(-65-28)$ & $0.97(0.96-0.98)$ \\
\hline & 20 & Status & $2.3(0-6)$ & $0.71(0.60-0.80)$ & $2.7(0-5)$ & $0.48(0.42-0.57)$ & $11.4(0-36)$ & $0.59(0.39-0.71)$ & $69.4(1-153)$ & $0.91(0.87-0.93)$ \\
\hline
\end{tabular}


Consultant of: AbbVie, Boehringer Ingelheim, Celgene, Eli Lilly, Galapagos, Janssen, Novartis, Pfizer and UCB, Grant/research support from: AbbVie, Novartis, Pfizer and UCB, Robert G Lambert Consultant of: Parexel and Pfizer, Iris Eshed: None declared, Susanne Juhl Pedersen Speakers bureau: MSD, Pfizer, AbbVie, Novartis and UCB, Consultant of: AbbVie and Novartis, Grant/research support from: AbbVie, MSD, and Novartis, Maria Stoenoiu: None declared, Simon Krabbe: None declared, Paul Bird Speakers bureau: Janssen, Abbvie, UCB, Celgene, BMS, Novartis, Pfizer, Gilead, Eli-Lilly, Consultant of: Janssen, Abbvie, UCB, Celgene, BMS, Novartis, Pfizer, Gilead, Eli-Lilly, Violaine Foltz: None declared, Ashish Jacob Mathew: None declared, Frederique Gandjbakhch None declared, Joel Paschke: None declared, Philippe Carron Speakers bureau: Pfizer, MSD, Novartis, BMS, AbbVie, UCB, Eli Lilly, Gilead and Celgene, Consultant of: Pfizer, MSD, Novartis, BMS, AbbVie, UCB, Eli Lilly, Gilead and Celgene, Grant/research support from: UCB, MSD and Pfizer, Gabriele De Marco: None declared, Helena Marzo-Ortega Speakers bureau: AbbVie, Celgene, Janssen, Lilly, Novartis, Pfizer, Takeda and UCB, Grant/research support from: Janssen and Novartis, Anna Enevold Fløistrup Poulsen: None declared, Jacob L Jaremko: None declared, Philip G Conaghan Speakers bureau: AbbVie, AstraZeneca BMS, Eli Lilly, EMD Serono, Flexion Therapeutics, Galapagos, Gilead, Novartis, Pfizer and Stryker, Consultant of: AbbVie, AstraZeneca, BMS, Eli Lilly, EMD Serono, Flexion Therapeutics, Galapagos, Gilead, Novartis, Pfizer and Stryker, Mikkel Østergaard Speakers bureau: Abbvie, BMS, Boehringer-Ingelheim, Celgene, Eli-Lilly, Hospira, Janssen, Merck, Novartis, Pfizer, Regeneron, Roche, Sandoz, Sanofi and UCB, Consultant of: Abbvie, BMS, Boehringer-Ingelheim, Celgene, Eli-Lilly, Hospira, Janssen, Merck, Novartis, Pfizer, Regeneron, Roche, Sandoz, Sanofi and UCB, Grant/research support from: Abbvie, BMS, Boehringer-Ingelheim, Celgene, Eli-Lilly, Hospira, Janssen, Merck, Novartis, Pfizer, Regeneron, Roche, Sandoz, Sanofi and UCB

DOI: 10.1136/annrheumdis-2021-eular.755

\section{OP0150 MODELLING IN INTERSTITIAL LUNG DISEASE ASSOCIATED WITH SYSTEMIC SCLEROSIS USING HIGH DIMENSIONAL IMAGE ANALYSIS}

M. Maciukiewicz ${ }^{1}$, J. Schniering ${ }^{1}$, H. Gabrys ${ }^{2}$, M. Brunner ${ }^{1}$, C. Blüthgen ${ }^{3}$, C. Meier ${ }^{1}$, M. Guckenberger ${ }^{2}$, H. Fretheim ${ }^{4}$, A. M. Hoffmann-Vold ${ }^{4}$, O. Distler ${ }^{1}$, T. Frauenfelder ${ }^{3}$, S. Tanadini-Lang ${ }^{2}$, B. Maurer ${ }^{1,5}{ }^{1}$ Center of Experimental Rheumatology, Department of Rheumatology, University of Zurich, Zurich, Switzerland; ${ }^{2}$ Department of Radiation Oncology, University Hospital

Zurich, University of Zurich, Zurich, Switzerland; ${ }^{3}$ Institute of Diagnostic and Interventional Radiology, University Hospital Zurich, University of Zurich, Zurich Switzerland; ${ }^{4}$ Institute of Clinical Medicine, University of Oslo, Rheumatology, Oslo University Hospital, Oslo, Norway; ${ }^{5}$ Department of Rheumatology and Immunology, University Hospital Bern, Bern, Switzerland

Background: The interstitial lung disease (ILD) associated with connective tissue diseases including systemic sclerosis (SSc) is heterogenous disease characterized by reduced survival of approximately 3 years (1). "Radiomics" is a field of research which describes the in-depth analysis of tissues by computational retrieval of high-dimensional quantitative features from medical images (2). Our previous study suggested capacity of radiomics features to differentiate between "high" and "low" risk groups for lung function decline in two independent cohorts (3)

Objectives:

- bTo develop robust, machine learning (ML) workflow for "radiomics" data in SSc-ILD to select optimal methods for prediction.

- oTo predict the time to individual lung function decline defined as defined by the time to a relative decline of $\geq 15 \%$ in Forced Vital Capacity (FVC) $\%$ as previously (3), using workflow.

Methods: We investigated two cohorts of SSc-ILD: 90 patients (76.7\% female, median age 57.5 years) from the University Hospital Zurich and 66 patients (75.8\% female, median age 61.0 years) from Oslo University Hospital's. Patients were retrospectively selected if (3): a) diagnosed with early/mild SSc according to the Very Early Diagnosis of Systemic Sclerosis (VEDOSS) criteria, b) presence of ILD on HRCT as determined by a senior radiologist. For every subject, we defined 1,355 robust radiomic features from HRCT images. The follow-up period was defined as the time interval between baseline visit and the last available follow-up visit.

We have developed a systematic computational workflow to build predictive $M L$ models. To reduce the number of redundant radiomic features, we applied correlation thresholds. We applied distinct methods including 1) Lasso Penalized Regression for feature selection, and 2) Random Forest (RF) for modeling using the R package 'caret'. To select the optimal ML model, we randomly divided derivation cohort into Training (70\%) and Holdout (30\%) sets and applied fivefold cross-validation ( $5 \mathrm{kCV}$ ) for feature and classifier selection on Training set only.

Results: We have investigated various methods to select the optimal set of predictive radiomic features. Since the $M L$ model performance is affected by both feature, and classifier selection, we assessed these factors first.

Results from feature filtering and selection, suggested that the combination of correlation threshold of 0.9 with Lasso regression proved best. As we perform feature selection in $5 \mathrm{k}$ CV workflow, features present in at least 2 sets entered model optimization step.

During model selection, we selected RF classifier. We detected positive correlation between actual and predicted values with Spearman's rho $=0.313, p=0.167$ and Spearman's rho $=0.341, \mathrm{p}=0.015$ in Oslo and Holdout sets respectively, as shown on Figure 1. The percentage of variance remained modest for both Holdout $(\mathrm{Rsq}=0.104)$ and Oslo $(\mathrm{Rsq}=0.126)$ datasets
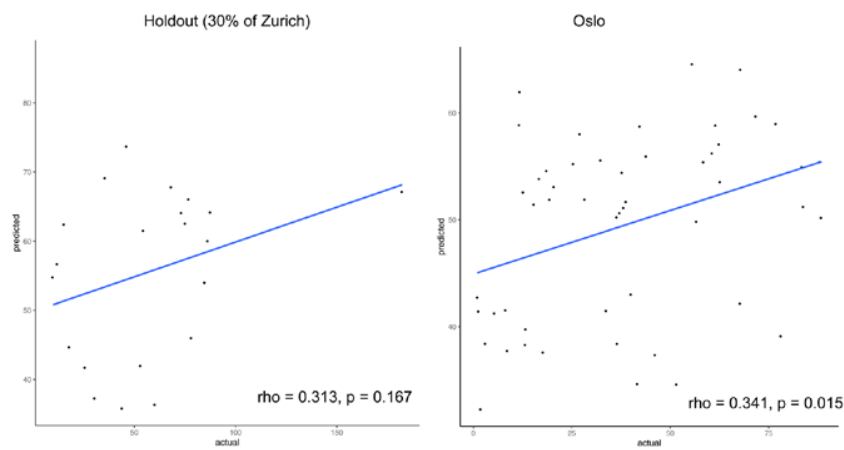

Figure 1. Performance of the best, RF classifier shown as scatterplot between actual and predicted values of individual time to lung decline.

Conclusion: In summary, we: (1) developed ML workflow that allowed to select o optimal methodology for modeling (i.e., feature and classifier selection), and (2) provide models that predicted time to individual lung function decline, characterized by significant correlation between predicted and actual values.

\section{REFERENCES:}

[1] Hansell DM, Goldin JG, King TE, Jr., Lynch DA, Richeldi L, Wells AU. CT staging and monitoring of fibrotic interstitial lung diseases in clinical practice and treatment trials: a position paper from the Fleischner Society. Lancet Respir Med. 2015;3(6):483-96.

[2] Lambin, P. et al. Radiomics: extracting more information from medical images using advanced feature analysis. Eur. J. Cancer 48, 441-446 (2012).

[3] Schniering J. et al. Resolving phenotypic and prognostic differences in interstitial lung disease related to systemic sclerosis by computed tomography-based radiomics. https://www.medrxiv.org/content/10.1101/2020.06.09.2 0124800v1

Disclosure of Interests: None declared

DOI: 10.1136/annrheumdis-2021-eular.2517 